\title{
Evaluation of gas-liquid separation performance of natural gas filters
}

\author{
Li Baisong, Ji Zhongli* and Yang Xue \\ School of Mechanical and Electronic Engineering, China University of Petroleum, Beijing 102249, China
}

\begin{abstract}
Fibrous filters are often used to remove contaminants including both dusts and liquid droplets from natural gas. This paper aims to evaluate the gas-liquid separation performance of three types of cartridge filters used in the West-East natural gas transmission project. The comparison of the original pressure drop of clean filters and the evolution of pressure drop as liquid droplets deposited in the filter media are described. The original pressure drops of these filters were similar but the pressure drops at a steady state were different. Fractional efficiency was used to study the separation performance of cartridge filters. Droplets at the outlet of the filters had small diameters, no more than $3 \mu \mathrm{m}$, but were very numerous. The effect of filtration velocity on gas-liquid separation performance was analyzed. Higher filtration velocity indicated better gas-liquid separation performance. Finally the quality factor related to pressure drop and filtration efficiency was applied to evaluate the gas-liquid separation performance.
\end{abstract}

Key words: Filtration, natural gas, gas-liquid separation, fractional efficiency, pressure drop

\section{Introduction}

Natural gas from different gas fields includes both dusts and liquid droplets. These small droplets and oil mist existing in natural gas seriously affect the operating cycle of gas transmission pipelines and large centrifugal compressors. However, it is very difficult to separate these liquid aerosols from natural gas. It was reported that some filters used in natural gas transmission pipelines were low in gas-liquid separation performance and short in service life ( $\mathrm{Li}, 2004)$. Consequently, there is a need to evaluate the gasliquid separation performance of filters used in natural gas transmission pipelines and to give some suggestions about filter materials and filter structure.

A large amount of research has been concerned with the gas filtration of solid aerosols (Destephen and Choi, 1996; Walsh, 1996; Thomas et al, 2001; Bénesse et al, 2006; Huang et al, 2006; Song et al, 2006). In contrast, little work so far has been dedicated to the filtration of liquid droplets from gas. Contal et al (2004) gave a description of clogging of a fiber filter by submicron droplets and divided the filtration process into four stages. In the first stage the pressure drop and penetration increased slowly as a small surface mass deposited. In the second stage the penetration increased exponentially until reaching a maximum. The third stage was characterized by a sharp rise in efficiency coinciding with an exponential increase in pressure drop. Finally, a pseudostationary state was established. Letts et al (2003) conducted tests to observe glass, polyester, and polyaramid fibers microscopically as these fibers collected liquid droplets.

*Corresponding author. email: jizhongli63@vip.sina.com Received October 22, 2008
They suggested that using higher surface energy fibers in mist filters might allow lower levels of liquid retention that resulted in wet filters with a lower pressure drop. Hajra et al (2003) studied the effects of temperature, humidity, and filter media with the addition of polymer nanofibers on gas/ liquid filtration performance. Charvet et al (2008) looked into such operation parameters as filtration velocity and the concentration of liquid droplets influencing pressure drop and filtration efficiency of gas-liquid filtration with a horizontal filter. Mullins et al $(2004 ; 2005$; 2006) carried out extensive experiments to investigate the wetting processes of a fiberliquid system microscopically during air filtration. Vasudevan and Chase (2004) used a novel combination of two types of glass media to get better performance in terms of capture efficiency and quality factor.

There are some discrepancies of evolution of filtration efficiency as liquid droplets deposit on filters. Some studies showed that the liquid collected by the filter generated a reduction in efficiency (Contal et al, 2004; Rayor and Leith, 2000; Frising et al, 2005). Rayor and Leith (2000) thought the presence of liquid on fiber surfaces could lower overall efficiency because some fiber sections were unavailable for droplet collection. In contrast, Conder and Liew (1989) observed filtration efficiency increased with the loading of liquid aerosols.

However, little literature on gas-liquid filtration performance of cartridge filters is available (Li et al, 2007). The aim of the present work is to evaluate the gas-liquid separation performance of natural gas cartridge filters. Several cartridge filters used in the West-East natural gas transmission project (a famous natural gas pipeline which transports natural gas from West China to East China) have been evaluated for pressure drop and filtration efficiency. 


\section{Experimental}

\subsection{Experimental apparatus}

The experimental set-up illustrated in Fig. 1 was composed of a droplet generator unit, a series of filter holders, and a sampling unit. Several cartridge filters mostly used in natural gas transmission pipelines were installed horizontally in the holders. Through acrylic glass holders, the filtration process was observed conveniently. A liquid collector was put at the inlet of the test cartridge filters to collect the liquid deposited on the filter holder; and another liquid collector was put at the outlet to collect the drainage from the cartridge filters. The pressure drop across the filter was monitored continuously with a U-tube pressure gauge.

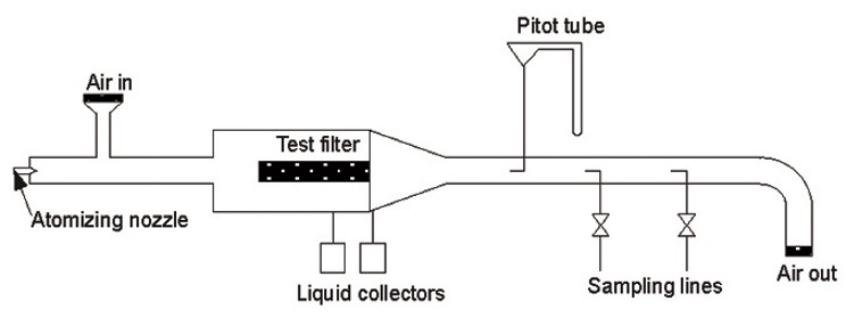

The mists were generated by an air atomizing nozzle SU11 (Spraying Systems Co., Shanghai, China). The generated liquid was di-2-ethylhexyl sebacate (DEHS) with a density of $913 \mathrm{~kg} / \mathrm{m}^{3}$ and very low saturated vapor pressure. The liquid and compressed air were mixed internally to produce an atomized spray.

A Welas 2000 light-scattering spectrometer (Palas, Karlsruhe, Germany) which determines particle concentration and particle size was used to measure the liquid aerosols at the outlet of the test cartridge filter. It has a measurement range of $0.3-40 \mu \mathrm{m}$ and a small measurement volume for concentrations up to $10^{5}$ particles $/ \mathrm{cm}^{3}$.

\subsection{Characteristics of the cartridge filters}

Three types of cartridge filters used in the West-East natural gas transmission project were tested (Table 1). The packing density of the filter media was calculated as follows:

$$
\alpha=\frac{m_{\mathrm{f}}}{V \rho_{\mathrm{f}}}
$$

where $m_{\mathrm{f}}$ is the mass of the fibers in the filter, $\mathrm{kg} ; V$ is the volume of the filter, $\mathrm{m}^{3}$; and $\rho_{\mathrm{f}}$ is the density of the fibers, $\mathrm{kg} / \mathrm{m}^{3}$.

Fig. 1 Experimental set-up

Table 1 Characteristics of the cartridge filters tested

\begin{tabular}{|c|c|c|c|c|c|c|}
\hline Item No. & Material & $\begin{array}{l}\text { Outside diameter } \\
\mathrm{mm}\end{array}$ & $\begin{array}{l}\text { Filter thickness } \\
\qquad \mathrm{mm}\end{array}$ & Packing density & $\begin{array}{l}\text { Length } \\
\mathrm{mm}\end{array}$ & Type \\
\hline $\mathrm{A}$ & Cellulose & 92.3 & 0.58 & 0.27 & 981 & Pleated \\
\hline $\mathrm{B}$ & Cellulose and acrylicester-styrene copolymer & 92.1 & 0.44 & 0.22 & 980 & Pleated \\
\hline $\mathrm{C}$ & Glass & 90.8 & 11.3 & 0.04 & 980 & Unpleated \\
\hline
\end{tabular}

\subsection{Experimental methods}

To shorten the clogging process of filtration, a high mass concentration of liquid droplets was used. This could not be measured by the Welas 2000 light-scatlering spectrometer as it was out of the range of measurement. The mass concentration was measured by comparison of the weight changes of liquid in the liquid tank supplying the spraying nozzle. The mists measured by a Malvern 2600 laser diffraction particle sizer (Malvern Instruments Ltd, Worcestershire, UK) had a Sauter mean diameter (SMD) of approximately $20 \mu \mathrm{m}$ and an index ranging from 2.1 to 2.6 .

Both the light-scattering spectrometer (Welas 2000) and the membrane filter sampling system were used to measure the mass concentration of outlet liquid droplets. A glass-fiber membrane filter was used in the membrane filter sampling system, which has a very high separation efficiency (more than $99.97 \%$ at $0.3 \mu \mathrm{m}$ ). Comparing the results from these two measuring systems, the repeatability and reliability of experimental results could be clarified.
Fig. 2 presents the comparison of the outlet mass concentration of a test filter measured with two methods. The test was carried out with cartridge filter $\mathrm{A}$ at a filtration velocity of $0.04 \mathrm{~m} / \mathrm{s}$ and an inlet mass concentration of $15 \mathrm{~g} / \mathrm{m}^{3}$. The test was conducted three times under the same conditions. The membrane filter was weighed after 80 minutes. The agreement of experimental results from two methods shows the level of repeatability and reliability of the experimental results.

\section{Results and discussion}

\subsection{Evolution of pressure drop}

Fig. 3 shows the relationship between pressure drop and filtration velocity of clean cartridge filters. Pressure drop was a nearly linear function of filtration velocity. The three types of clean filters had similar pressure drops at a given filtration velocity of $0.02-0.10 \mathrm{~m} / \mathrm{s}$.

Fig. 4 shows the evolution of pressure drop when liquid 

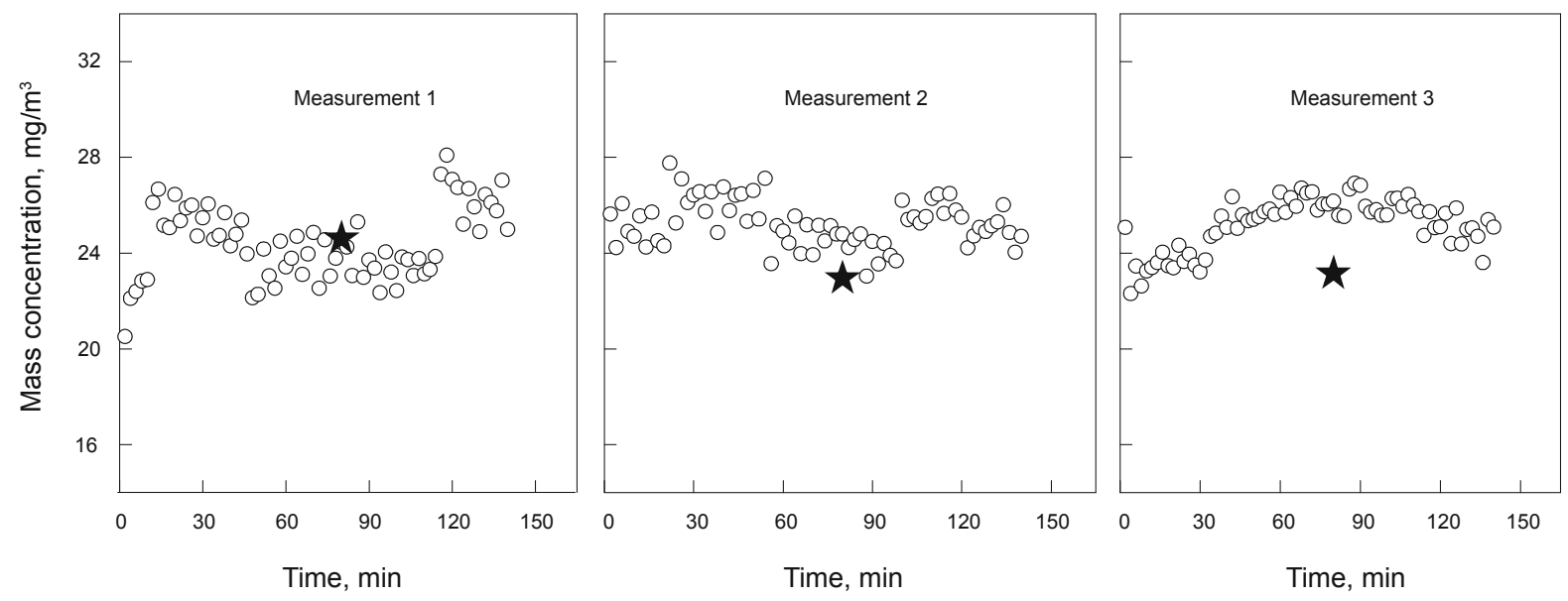

Fig. 2 Comparison of two measurement methods $\circ$ Welas measurement; $\star$ Weighing measurement

droplets deposited in the filter. The experiments were performed at a filtration velocity of $0.06 \mathrm{~m} / \mathrm{s}$ and an inlet mass concentration of $15 \mathrm{~g} / \mathrm{m}^{3}$. The pressure drop increased as liquid droplets deposited in the filter. Finally, the pressure drops leveled off and the filtration reached a steady state.

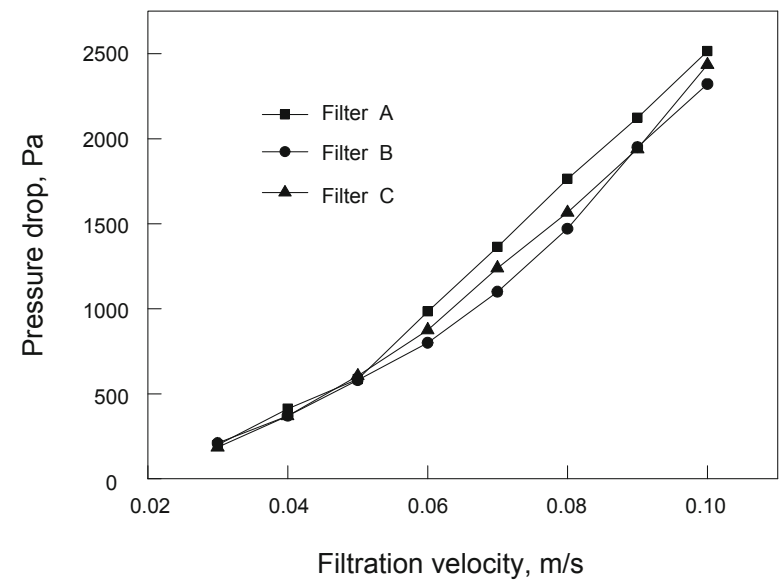

Fig. 3 Characteristics of original pressure drop of clean filters

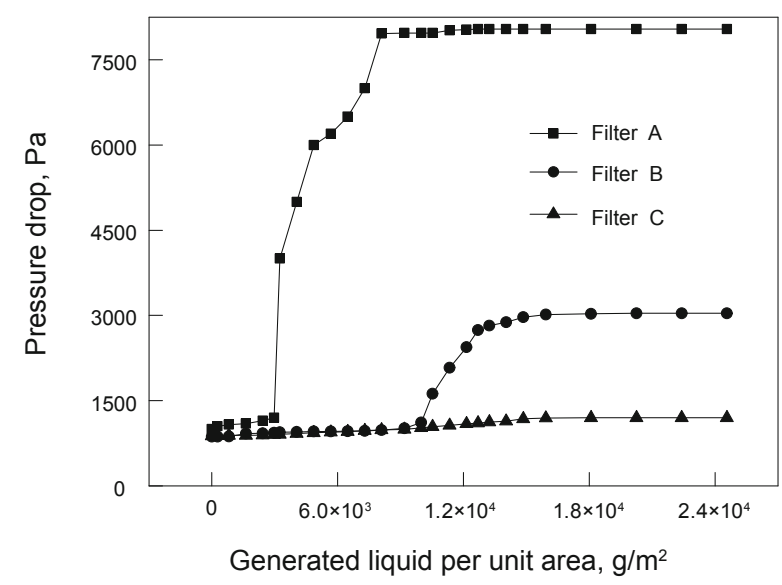

Fig. 4 Evolution of pressure drop at a filtration velocity of $0.06 \mathrm{~m} / \mathrm{s}$
The change of pressure drop in filter A and filter B could be divided into three stages. In the beginning, the pressure drop increased slowly as a small number of liquid droplets deposited. Then, the pressure drop increased sharply after the number of droplets deposited in the filter reached a critical value. Finally, the pressure drop reached a plateau. In contrast, the filter $\mathrm{C}$ having a low packing density did not have a threshold of sharp pressure drop. Filter A and B had similar structures. However, filter B was an mixture of acrylicesterstyrene copolymer and cellulose, and filter A just consisted of cellulose. The added acrylicester-styrene copolymer could lower the surface tension of the filter medium, which resulted in less liquid retained in the filter media and then a decrease in the pressure drop. Fig. 5 shows the SEM (scanning electronic microscopy) images of the used and unused filters. The nature of filter had a great effect on the liquid retained in the filter. The more the liquid retained in the filter the higher the pressure drop.

\subsection{Droplet mass concentration at the outlet}

Fig. 6 shows the droplet mass concentrations at the outlet of the filters when the pressure drop reached a steady state. The experiments were carried out at a filtration velocity of $0.06 \mathrm{~m} / \mathrm{s}$ and an inlet droplet mass concentration of $15 \mathrm{~g} / \mathrm{m}^{3}$. The mass concentrations at the filter outlet were measured with the Welas 2000 spectrometer every 5 minutes. The droplet mass concentration at the outlet did not change when the pressure drop remained constant. The droplet mass concentration at the outlet was determined by droplet size and droplet number concentration. Fig. 7 presents the droplet size distributions at the outlets of the three filters. Small droplets were densely distributed at the outlet of the filters in the process of gas-liquid filtration. The mean diameter of outlet droplets was about $1 \mu \mathrm{m}$. The droplet number concentrations at the outlets of filters A, B, and C were 36,925, 7,971, and 25,261 particles $/ \mathrm{cm}^{3}$, respectively. The droplet size distributions at the outlet of filters $\mathrm{B}$ and $\mathrm{C}$ were similar, but the droplet number concentration at the outlet of filter $\mathrm{C}$ 
was greater than that at the outlet of filter B. As a result, the droplet mass concentration at the outlet of filter $\mathrm{C}$ was larger than that at the outlet of filter B, as shown in Fig. 6. When the droplets deposited on the fibers, the packing density and equivalent fiber diameter of the filter may be different from its initial state. The filter of higher packing density and smaller equivalent fiber diameter at the steady state had a better gasliquid separation performance.

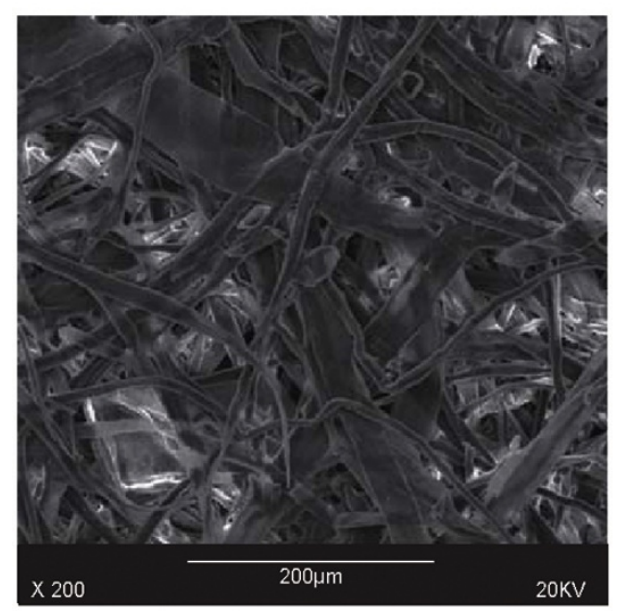

(a) Unused filter $A$

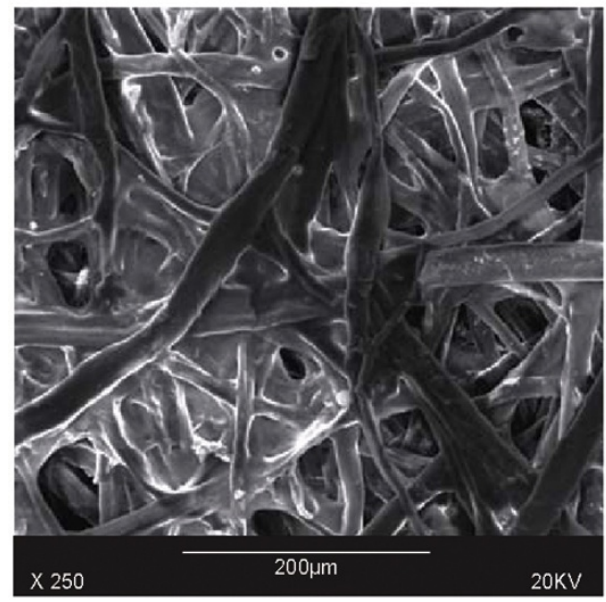

(c) Unused filter B

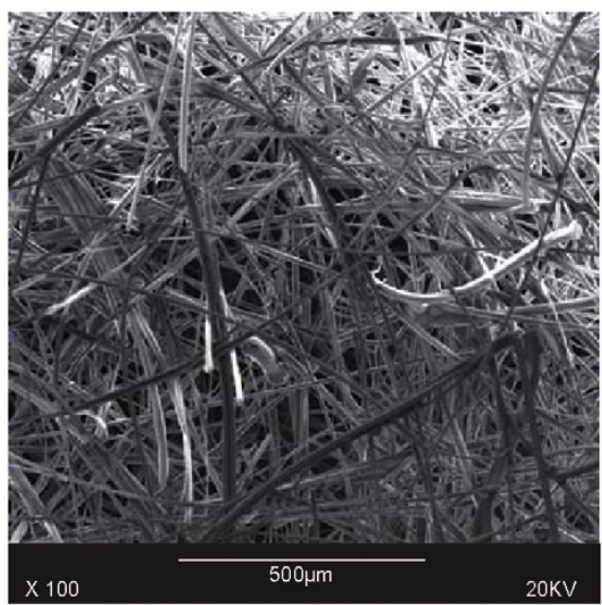

(e) Unused filter $\mathrm{C}$

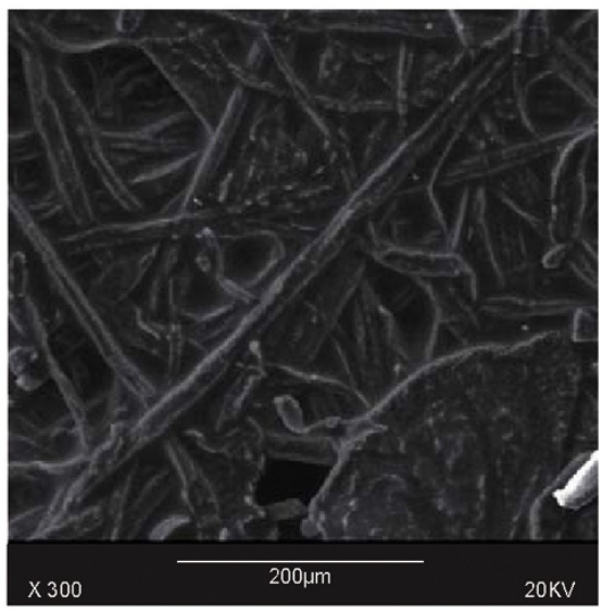

(b) Used filter A

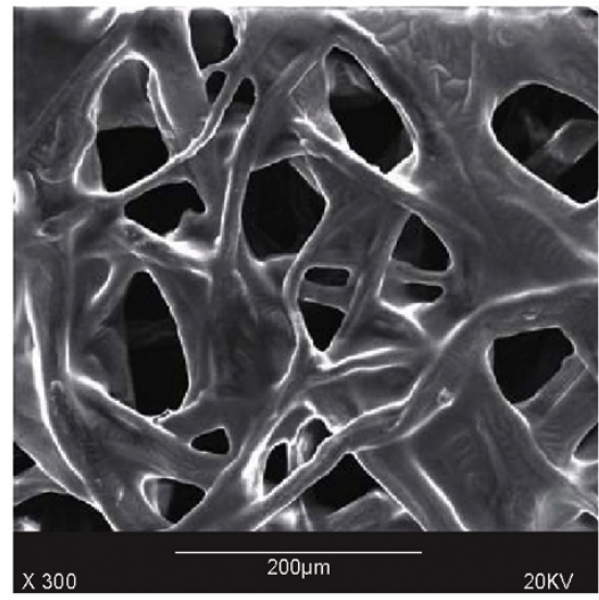

(d) Used filter B

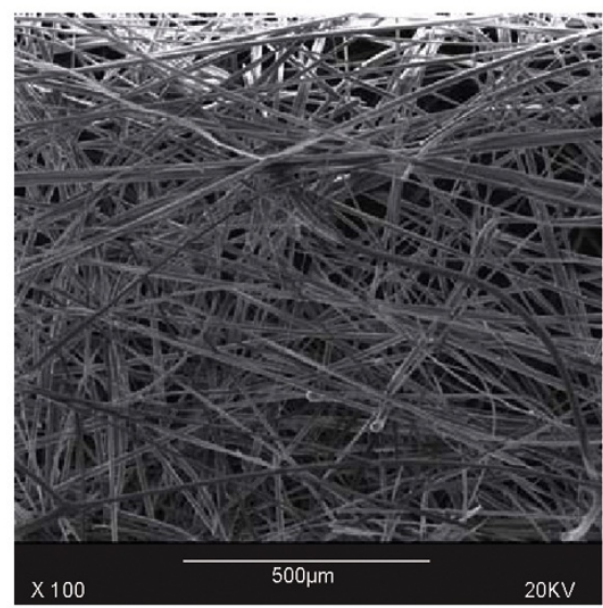

(f) Used filter C

Fig. 5 SEM images of the used and unused filters 


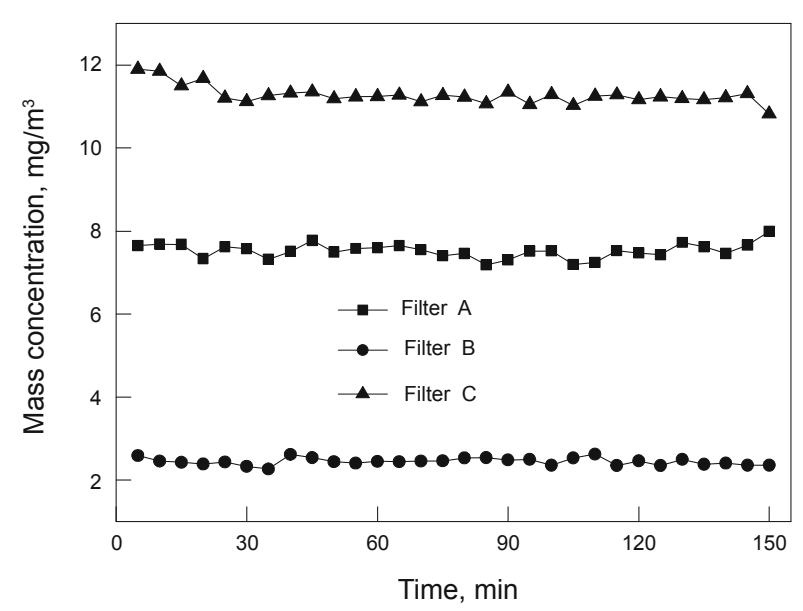

Fig. 6 Droplet mass concentrations at the outlets of the filters at a steady state

\subsection{Fractional efficiency for different-sized droplets}

For a specific droplet diameter, fractional efficiency can be calculated as follows:

$$
\eta_{\mathrm{F}}=\left(1-N_{\text {outlet }} / N_{\text {inlet }}\right) \times 100 \%
$$

where $N_{\text {outlet }}$ and $N_{\text {inlet }}$ are the number of droplets at the outlet and the inlet, respectively.

The outlet droplets were measured by the light-scattering spectrometer (Welas 2000). And the inlet droplets were measured by the laser diffraction particle sizer (Malvern 2600), which has a different resolution from the lightscattering spectrometer. In order to calculate fractional efficiency, the results measured by the laser diffraction particle sizer should be changed. The droplet size distribution at the inlet of the filter was obtained according to the RosinRammler distribution function (Zheng et al, 2006). Fig. 8 shows the comparison of fractional efficiency of different cartridge filters for different-sized droplets. The experiments were carried out at a filtration velocity of $0.06 \mathrm{~m} / \mathrm{s}$ and a droplet mass concentration of $15 \mathrm{~g} / \mathrm{m}^{3}$ at the inlet.

The filters were very effective for liquid droplets larger than $2 \mu \mathrm{m}$. Filter B had higher fractional efficiency than the other two filters for droplets smaller than $2 \mu \mathrm{m}$. Therefore, filter B should have lower mass concentration at the outlet than the others. As to the comparison of filter A and filter $C$, it seemed a bit more complex. Filter A was more effective than filter $\mathrm{C}$ for droplets larger than $0.8 \mu \mathrm{m}$ but less effective for droplets smaller than $0.8 \mu \mathrm{m}$.

\subsection{Influence of filtration velocity}

Fig. 9 represents the changes in the pressure drop and the droplet mass concentration at the outlet at different filtration rates. The experiments were carried out with the same inlet droplet mass concentration of $15 \mathrm{~g} / \mathrm{m}^{3}$. Higher filtration velocity led to higher pressure drop and lower droplet mass concentration at the outlet of the filter. Similar results have also been obtained by other researchers (Contal et al, 2004; Frising et al, 2005; Charvet et al, 2008).

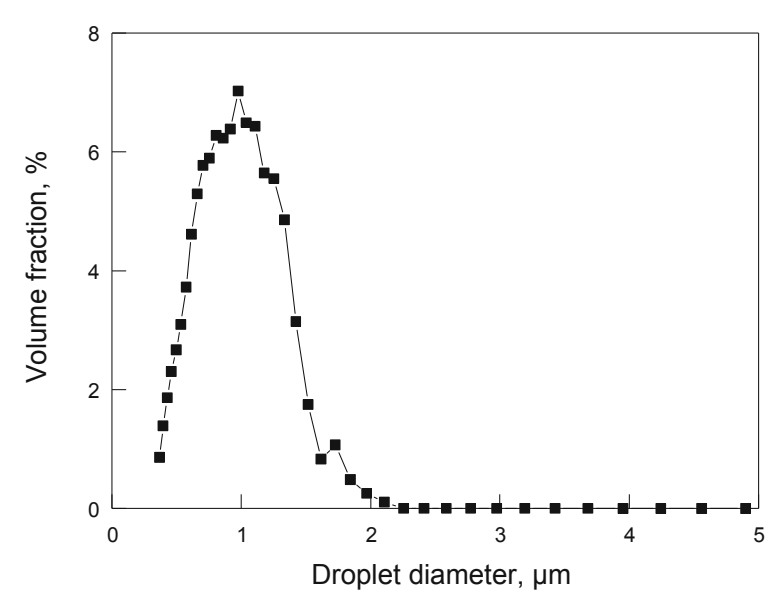

(a) Filter A

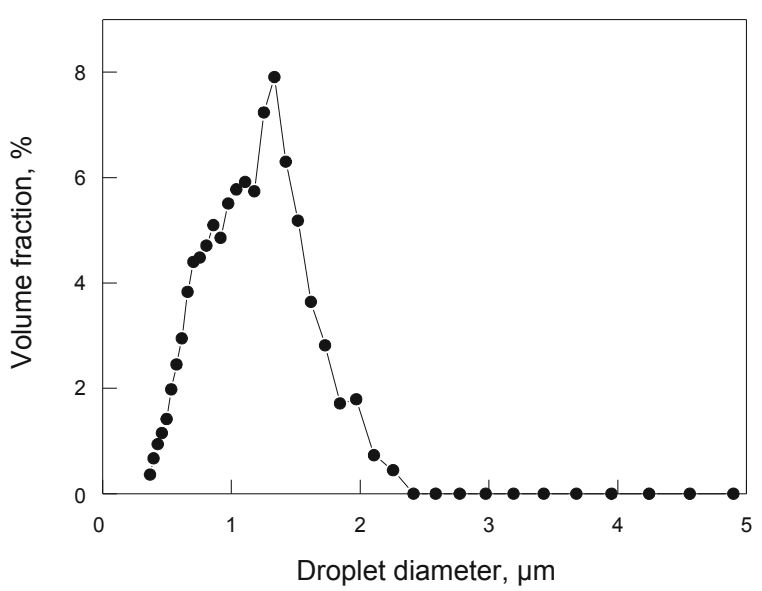

(b) Filter B

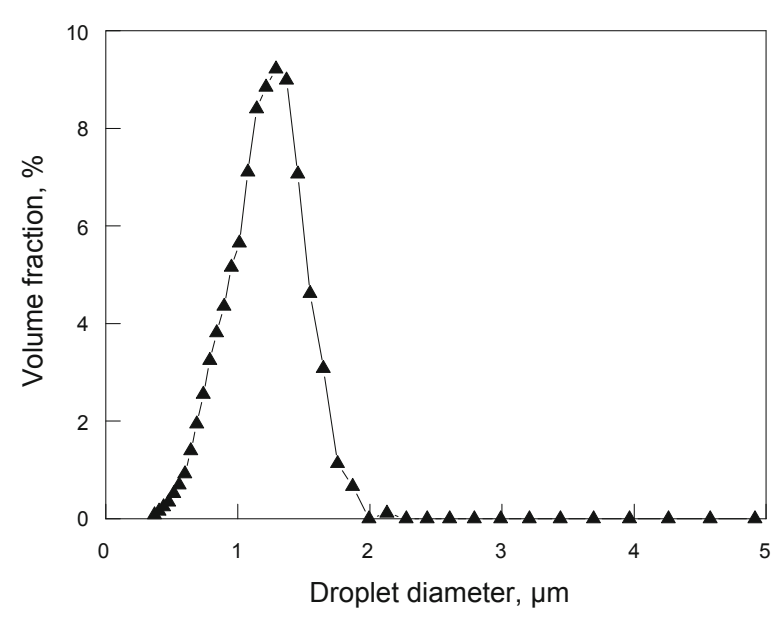

(c) Filter C

Fig. 7 Outlet droplet size distributions at a filtration velocity of $0.06 \mathrm{~m} / \mathrm{s}$

\subsection{Comprehensive evaluation}

Pressure drop and filtration efficiency are two important factors to evaluate the performance of filter media. Better filter performance means higher filtration efficiency and lower pressure drop. Generally, pressure drop and filtration 


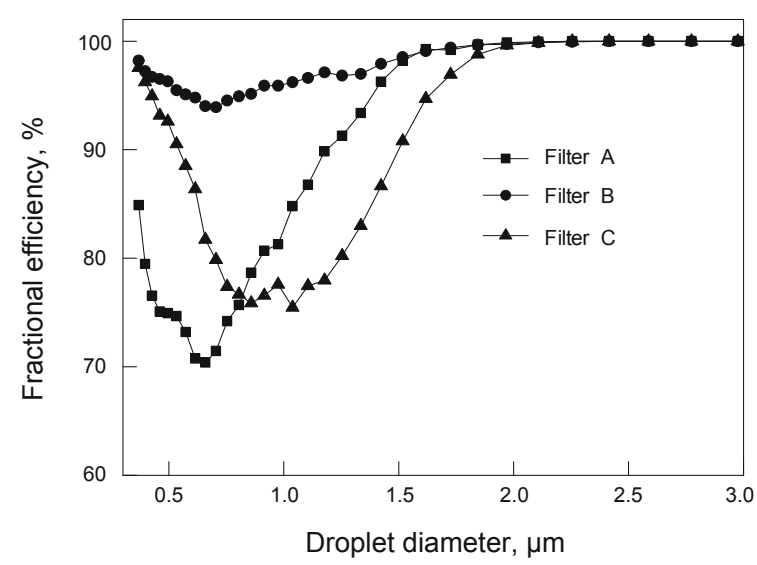

Fig. 8 Fractional efficiency for different-sized droplets

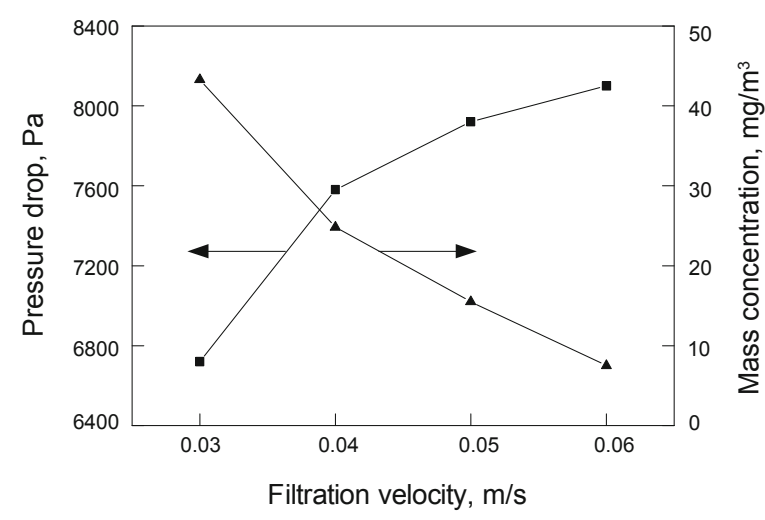

(a) Filter $\mathrm{A}$

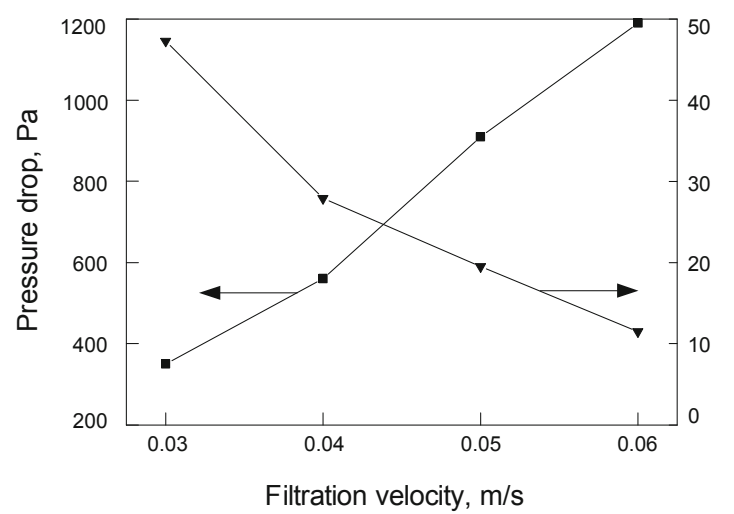

(b) Filter $\mathrm{C}$

Fig. 9 Influence of filtration velocity on pressure drop and droplet mass concentration at the outlet of the filter

efficiency have the similar trend. Higher filtration efficiency sometimes leads to higher pressure drop. The quality factor, being independent of filter thickness, provides a convenient quality for comparing filter performance (Hajra et al, 2003). The higher quality factor indicates better performance of the filter media. The quality factor is given by:

$$
f_{\mathrm{q}}=\frac{-\ln \left(C_{\text {outlet }} / C_{\text {inlet }}\right)}{\Delta p}
$$

where $C_{\text {outlet }}$ and $C_{\text {inlet }}$ are mass concentrations of droplets at the outlet and inlet, respectively; and $\Delta p$ is the pressure drop through the filter.

Table 2 presents the comprehensive evaluation of three filters under the conditions of the inlet droplet mass concentration of $15 \mathrm{~g} / \mathrm{m}^{3}$ and the filtration velocities of 0.06 and $0.04 \mathrm{~m} / \mathrm{s}$. It can be seen that filter $\mathrm{C}$ had the highest quality factor, which meant it had the best filtration performance.

Table 2 Comprehensive evaluation of three cartridge filters

\begin{tabular}{ccccc}
\hline $\begin{array}{c}\text { Filtration velocity } \\
\mathrm{m} / \mathrm{s}\end{array}$ & Filter & $\begin{array}{c}C_{\text {oulet }} \\
\mathrm{g} / \mathrm{m}^{3}\end{array}$ & $\begin{array}{c}\Delta p \\
\mathrm{~Pa}\end{array}$ & $\begin{array}{c}f_{\mathrm{q}} \\
1 / \mathrm{kPa}\end{array}$ \\
\hline & $\mathrm{A}$ & 7.5 & 8100 & 0.408 \\
0.006 & $\mathrm{~B}$ & 2.3 & 3110 & 1.226 \\
& $\mathrm{C}$ & 11.5 & 1190 & 2.618 \\
\hline & $\mathrm{A}$ & 24.8 & 7580 & 0.367 \\
0.004 & $\mathrm{~B}$ & 8.5 & 2640 & 1.230 \\
& $\mathrm{C}$ & 27.9 & 560 & 4.870 \\
\hline
\end{tabular}

\section{Conclusions}

1) A Welas 2000 light-scattering spectrometer and a high precision membrane filter sampling system were used to measure the mass concentration of liquid droplets. The agreement of the results from these two measurement methods showed the repeatability and reliability of experimental results.

2) The gas-liquid separation performance of three types of cartridge filters used in the West-East natural gas transmission project was investigated. These filters were very effective for liquid droplets larger than $2 \mu \mathrm{m}$.

3) The characteristics of the filter influenced the pressure drop and the filtration efficiency considerably. Structure optimization and surface treatment of the filter can improve gas-liquid separation performance.

4) The filtration velocity influenced significantly the gasliquid separation performance of the filter in the range from 0.03 to $0.06 \mathrm{~m} / \mathrm{s}$. Higher filtration velocity led to higher pressure drop and lower droplet mass concentration at the outlet of the filter.

\section{References}

Bénesse M, LeCoq L and Solliec C. Collection efficiency of a woven filter made of multifiber yarn: experimental characterization during loading and clean filter modeling based on a two-tier single fiber approach. Journal of Aerosol Science. 2006. 37: 974-989

Charvet A, Gonthier Y, Bernis A, et al. Filtration of liquid aerosols with a horizontal fibrous filter. Chemical Engineering Research and Design. 2008. 86: 569-576

Conder J R and Liew T P. Fine mist filtration by wet filters-II: efficiency of fibrous filters. Journal of Aerosol Science. 1989. 20: 45-57 
Contal P, Simao J, Thomas D, et al. Clogging of fiber filters by submicron droplets: phenomena and influence of operating conditions. Journal of Aerosol Science. 2004. 35: 263-278

Destephen J A and Choi K J. Modeling of filtration processes of fibrous filter media. Separation Technology. 1996. 6: 55-67

Frising T, Thomas D, Bémer D, et al. Clogging of fibrous filters by liquid aerosol particles: experimental and phenomenological modeling study. Chemical Engineering Science. 2005. 60: 2751-2762

Hajra M G, Mehta K and Chase G G. Effects of humidity, temperature, and nanofibers on drop coalescence in glass fiber media. Separation and Purification Technology. 2003. 30: 79-88

Huang B, Yao Q, Li S Q, et al. Experimental investigation on the particle capture by a single fiber using microscopic image technique. Powder Technology. 2006. 163: 125-133

Letts G M, Rayor P C and Schumann R L. Selecting fiber materials to improve mist filters. Journal of Aerosol Science. 2003. 34: 14811492

Li B S, Ji Z L and Chen H Y. Study of the gas-liquid separation performance of natural gas filters. Natural Gas Industry. 2007. 10: 123-125 (in Chinese)

Li K. Actuality and improvement of large natural gas filter. Oil Field Equipment. 2004. 33: 124-126 (in Chinese)

Mullins B J, Agranovski I E, Braddock R D, et al. Effect of fiber orientation on fiber wetting processes. Journal of Colloid and Interface Science. 2004. 269: 449-458

Mullins B J, Braddock R D, Agranovski I E, et al. Observation and modelling of clamshell droplets on vertical fibers subjected to gravitational and drag forces. Journal of Colloid and Interface Science. 2005. 284: 245-254

Mullins B J, Braddock R D, Agranovski I E, et al. Observation and modelling of barrel droplets on vertical fibers subjected to gravitational and drag forces. Journal of Colloid and Interface Science. 2006. 300: 704-712

Rayor P C and Leith D. The influence of accumulated liquid on fibrous filter performance. Journal of Aerosol Science. 2000. 31: 19-34

Song C B, Park H S and Lee K W. Experimental study of filter clogging with monodisperse PSL particles. Powder Technology. 2006. 163: 152-159

Thomas D, Penicot P, Contal P, et al. Clogging of fibrous filters by solid aerosol particles: experimental and modeling study. Chemical Engineering Science. 2001. 56: 3549-3561

Vasudevan G and Chase G G. Performance of B-E-glass fiber media in coalescence filtration. Journal of Aerosol Science. 2004. 35: 83-91

Walsh D C. Recent advances in the understanding of fibrous filter behaviour under solid particle load. Filtration \& Separation. 1996. 33: 501-506

Zheng G B, Kang T H, Chai Z Y, et al. Applied the Rosin-Rammler distribution function to study on the law of coal dust particle-size distribution. Journal of Taiyuan University of Technology. 2006. 3: 64-66 (in Chinese)

(Edited by Sun Yanhua) 